\title{
Role of tumour necrosis factor- $\alpha$ receptor p75 in cigarette smoke-induced pulmonary inflammation and emphysema
}

\author{
A.I. D’hulst*, K.R. Bracke*, T. Maes*, J.L. De Bleecker", R.A. Pauwels*,', \\ G.F. Joos* and G.G. Brusselle*
}

ABSTRACT: Chronic obstructive pulmonary disease (COPD) is characterised by a local pulmonary inflammatory response to respiratory pollutants and by systemic inflammation. Tumour necrosis factor (TNF)- $\alpha$ has been implicated in systemic effects of COPD and operates by binding the p55 (R1) and p75 (R2) TNF- $\alpha$ receptors.

To investigate the contribution of each TNF- $\alpha$ receptor in the pathogenesis of COPD, the present study examined the effects of chronic air or cigarette smoke (CS) exposure in TNF- $\alpha$ R1 knockout (KO) mice, TNF- $\alpha$ R2 KO mice and wild type (WT) mice.

CS was found to significantly increase the protein levels of soluble TNF- $\alpha$ R1 (by four-fold) and TNF$\alpha$ R2 (by 10-fold) in the bronchoalveolar lavage of WT mice. After 3 months, CS induced a prominent pulmonary inflammatory cell influx in WT and TNF- $\alpha$ R1 KO mice. In TNF- $\alpha$ R2 KO mice, CS-induced pulmonary inflammation was clearly attenuated. After 6 months, no emphysema was observed in CSexposed TNF- $\alpha$ R2 KO mice in contrast to WT and TNF- $\alpha$ R1 KO mice. CS-exposed WT and TNF- $\alpha$ R1 KO mice failed to gain weight, whereas the body mass of TNF- $\alpha$ R2 KO mice was not affected.

These current findings suggest that both tumour necrosis factor- $\alpha$ receptors contribute to the pathogenesis of chronic obstructive pulmonary disease, but tumour necrosis factor- $\alpha$ receptor-2 is the most active receptor in the development of inflammation, emphysema and systemic weight loss in this murine model of chronic obstructive pulmonary disease.

KEYWORDS: Chronic obstructive pulmonary disease, cigarette smoking, emphysema, inflammation, tumour necrosis factor- $\alpha$ receptors, weight loss

hronic obstructive pulmonary disease (COPD) is a leading cause of chronic morbidity and mortality worldwide and its prevalence is still increasing $[1,2]$. COPD is a disease state characterised by airflow limitation that is not fully reversible. This airflow limitation is progressive and is associated with an abnormal inflammatory response of the lungs to noxious agents, such as cigarette smoke (CS). Inflammatory processes damage the lungs and lead to destruction of lung parenchyma (emphysema), an important structural abnormality present in COPD patients [3]. COPD is also associated with systemic effects, such as skeletal muscle dysfunction, weight loss (cachexia) and systemic inflammation, including abnormal concentrations of circulating cytokines and activation of inflammatory cells $[4,5]$.

Tumour necrosis factor (TNF)- $\alpha$, a powerful proinflammatory cytokine primarily produced by activated macrophages, is a key mediator of inflammation in both early and late events of the inflammatory cascade. TNF- $\alpha$ is also referred to as cachectin, a catabolic hormone [6], and has been implicated in the pathogenesis of a variety of lung diseases [7-11]. Increased TNF- $\alpha$ levels have been measured in sputum [12], bronchoalveolar lavage (BAL) [13] and in serum [14] of smokers. In contrast, in vitro studies report that smoke suppresses TNF- $\alpha$ production by lavaged or cultured alveolar macrophages and peripheral blood monocytes of humans and animals [15, 16]. Chronic systemic inflammation involving cytokines, such as interleukin-1 and TNF- $\alpha$, may be associated with cachexia, commonly seen in severe COPD patients [17].

TNF- $\alpha$ operates by binding to two structurally related, but functionally distinct, cell surface receptors, p55 (type 1, CD120a: R1) and p75 (type 2, CD120b: R2) TNF- $\alpha$ receptors. Both receptors are expressed on most cell types and function by recruitment of adaptor proteins [18]. Both
AFFILIATIONS

Depts of *Respiratory Diseases, and

\#Neurology, Ghent University

Hospital, Ghent, Belgium.

CORRESPONDENCE

A.I. D'hulst

Dept of Respiratory Diseases

Ghent University Hospital

De Pintelaan 185

B-9000 Ghent

Belgium

Fax: 3292402341

E-mail: an.dhulst@UGent.be

Received:

May 192005

Accepted after revision:

February 272006

SUPPORT STATEMENT

This study was supported by funding for Scientific Research Flanders Project Grant No G.0011.03 and the Concerted Research Initiative of the Ghent University, Project No BOF/ GOA 120.50 .698

European Respiratory Journal Print ISSN 0903-1936 Online ISSN 1399-3003 
receptors can be proteolytically cleaved and released as soluble forms that are capable of binding TNF- $\alpha$. The R1 appears to be responsible for activating the majority of inflammatory responses, host defences and cytotoxicity. The role of R2 is less understood; in addition to an accessory role, there is evidence that it modulates TNF- $\alpha$-mediated inflammation and activates cell death [19-22]. The actual involvement of TNF- $\alpha$ receptors in COPD pathogenesis remains vague. Studies demonstrated increased levels of soluble TNF- $\alpha$ receptors in sputum and serum of COPD patients [14, 23]. Using TNF- $\alpha$ receptor double knockout (KO) mice, it has recently been demonstrated that TNF- $\alpha$ and its receptors are central to acute CS-induced inflammation and connective tissue breakdown [7]. When TNF- $\alpha$ receptor double $\mathrm{KO}$ mice were exposed chronically to smoke for 6 months, the ensuing airspace enlargement was reduced by $70 \%$ compared with wild type (WT) animals [24]. LUCEY et al. [25] observed a decreased elastase-induced emphysema in TNF- $\alpha$ receptor-deficient mice. However, it is not known which TNF- $\alpha$ receptor is either required or sufficient to induce the CS-elicited influx of inflammatory cells and pulmonary emphysema. To examine which type of TNF- $\alpha$ receptor is involved in the pathogenesis of COPD, mice lacking either R1 (referred to as TNF- $\alpha$ $\mathrm{R} 1 \mathrm{KO}$ ) or R2 (referred to as TNF- $\alpha \mathrm{R} 2 \mathrm{KO}$ ) were used in a chronic model of CS-induced pulmonary inflammation and emphysema [26].

\section{METHODS}

\section{Animals}

Mice deficient for the TNF- $\alpha$ R1 (B6.129-Tnfrsf $1 a^{\text {tm1Mak }}$ ) and mice deficient for the TNF- $\alpha$ R2 (B6.129-Tnfrsf $1 b^{\text {tm1Mwm }}$ ) were obtained from The Jackson Laboratory (Bar Harbor, ME, USA). WT mice, used as controls, were $\mathrm{C} 57 \mathrm{Bl} / 6$ mice as suggested by The Jackson Laboratory. The local Ethics Committee for animal experimentation of Ghent University (Ghent, Belgium) approved all in vivo manipulations.

\section{Experimental design}

Three independent experiments were performed. Mice were exposed to air or CS for 3 months (first experiment, $n=6$ per group), 6 months (second experiment, $n=6$ per group) or 4.5 months (third experiment, $n=8$ per group).

\section{Smoke exposure}

Mice were exposed to CS as described previously [26]. In brief, groups of six or eight mice (aged 8 weeks) were exposed to the tobacco smoke of five cigarettes (Reference Cigarette 2R4F without filter; University of Kentucky, Lexington, KY, USA) four times a day with 30-min smoke-free intervals, 5 days week $^{-1}$. The smoke/air ratio used in this study was 1:6. The control group was exposed to air. Carboxyhaemoglobin levels in serum of smoke-exposed mice were $8.3 \pm 1.4$ versus $1.0 \pm 0.2 \%$ in air-exposed mice $(n=7)$.

\section{Body mass}

The mice were weighed $24 \mathrm{~h}$ after the last smoke exposure in the 3- and 6-month experiments; this was referred to as the final body weight. In the third experiment (4.5-month experiment), the body mass of the mice was measured weekly throughout the study period.

\section{Bronchoalveolar lavage}

The mice were killed $24 \mathrm{~h}$ after the last smoke exposure with an overdose of pentobarbital (Sanofi, Libourne, France) and a tracheal cannula was inserted. Hank's balanced salt solution (HBSS; $1 \mathrm{~mL}$ ), free of ionised calcium and magnesium, but supplemented with $0.05 \mathrm{mM}$ sodium EDTA, was instilled four times via the tracheal cannula and recovered by gentle manual aspiration. The four BAL fractions were centrifuged, the cell pellet was washed twice and finally resuspended in $1 \mathrm{~mL}$ of HBSS. A total cell count was performed in a Bürcker chamber and the differential cell counts (on a minimum of 400 cells), to enumerate neutrophils, macrophages and lymphocytes, were performed on cytocentrifuged preparations using standard morphological criteria after May-Grünwald-Giemsa staining. Flow cytometric analysis of the BAL cells was also performed to enumerate dendritic cells. The supernatants of the first BAL fraction $(1 \mathrm{~mL})$ were frozen at $-20^{\circ} \mathrm{C}$ for later analysis of cytokines and soluble TNF- $\alpha$ receptors.

\section{Preparation of lung single-cell suspensions}

Following BAL, the pulmonary and systemic circulation was rinsed. The left lung was used for histology and the right lung for the preparation of a cell suspension, as detailed previously $[26,27]$. Briefly, the lung was thoroughly minced, digested, subjected to red blood cell lysis, passed through a $50-\mu \mathrm{m}$ cell strainer and kept on ice until labelling. Cell counting was performed with a Z2 Beckman Coulter particle counter (Beckman Coulter, Ghent, Belgium).

\section{Labelling of BAL cells and lung single-cell suspensions for flow cytometry}

Cells were pre-incubated with $\mathrm{F}_{\mathrm{c}}$-receptor blocking antibody (anti-CD16/CD32, clone 2.4G2) to reduce nonspecific binding. Monoclonal antibodies used to identify mouse dendritic cells (DCs) populations were: biotinylated anti-CD11c (N418) and phycoerythrin-conjugated anti-IA ${ }^{\mathrm{b}}$ (AF6-120.1), followed by streptavidine-allophycocyanine (SAv-APC). Mouse T-cell populations were characterised with the following monoclonal antibodies: fluorescein isothiocyanate (FITC)-conjugated antiCD4 (L3T4), FITC-conjugated anti-CD8 (Ly-2), and biotinylated anti-CD3 (145-2C11). The additional marker used for activation was anti-CD69 (H1.2F3). Biotinylated anti-CD3 was revealed by incubation with SAv-APC. All antibodies were obtained from BD Pharmingen (Erembodegem, Belgium), except anti-CD11c (N418 hybridoma, a gift from M. Moser, Free University of Brussels, Belgium).

Cell suspensions were incubated with 7-amino-actinomycin (7AAD; BD Pharmingen) for the exclusion of dead cells. All labelling reactions were performed on ice in fluorescenceactivated cell sorter (FACS)-EDTA buffer.

Flow cytometry data acquisition was performed on a duallaser FACS Vantage ${ }^{\mathrm{TM}}$ flow cytometer running CELLQuest ${ }^{\mathrm{TM}}$ software (Becton Dickinson, Mountain View, CA, USA). FlowJo software (Ashland, OR, USA) was used for data analysis.

\section{Histology}

After excision of the right lung for preparation of single-cell suspensions, the left lung was fixated by a gentle infusion of fixative ( $4 \%$ paraformaldehyde) through the tracheal cannula 
by a continuous-release pump under pressure-controlled conditions [26]. After excision, the left lung was immersed in fresh fixative for $2 \mathrm{~h}$. The lung lobe was embedded in paraffin and cut in 3- $\mu \mathrm{m}$ transversal sections. Lung tissue samples were stained with haematoxylin and eosin and examined by light microscopy for histological sections.

\section{Quantification of emphysema}

Emphysema is a structural disorder characterised by destruction of the alveolar walls and enlargement of the alveolar spaces. Destruction of alveolar walls was determined by measuring the destructive index (DI) and enlargement of alveolar spaces by quantifying the mean linear intercept $(\mathrm{Lm})$, as described previously [26, 28].

Quantification of airspace enlargement was determined after 3, 4.5 and 6 months' smoke exposure by measuring the mean Lm, using image analysis software. Only sections without cutting artefacts, compression or hilar structures (airway or blood vessel with a diameter $>50 \mu \mathrm{m}$ ) were used in the analysis. The Lm was measured by placing a $100 \times 100 \mu \mathrm{m}$ grid over each field. The total length of each line of the grid divided by the number of alveolar intercepts gives the average distance between alveolated surfaces, or the Lm [28].

The destruction of alveolar walls was quantified by the DI [29]. A grid with 42 points that were at the centre of hairline crosses was superimposed on the lung field. Structures lying under these points were classified as normal (N) or destroyed (D) alveolar and/or duct spaces. Points falling over other structures, such as duct walls, alveolar walls, etc., did not enter into the calculations. The DI was calculated from the following formula:

$$
\mathrm{DI}=\mathrm{D} /(\mathrm{D}+\mathrm{N}) \times 100
$$

For each animal, 10 fields at a magnification of $\times 200$ were captured in a blinded fashion using a Zeiss KS400 image analyser platform (KS400; Zeiss, Oberkochen, Germany).

\section{Apoptosis}

To evaluate apoptosis of type II epithelial cells in lung tissue after 6 months of CS exposure, lung sections obtained from formalinfixed, paraffin-embedded lung lobes were subjected to an immunohistological terminal deoxynucleotidyltransferasemediated deoxyuridine triphosphate nick-end labelling (TUNEL)/prosurfactant protein C (proSPC) double-staining. At first, TUNEL staining was performed with the ApopTag ${ }^{\circledR}$ Plus Peroxidase In Situ Apoptosis Detection Kit (Chemicon International, Temecula, CA, USA) following the manufacturer's protocol. In a second step, sections were stained overnight with anti-proSPC (Chemicon International) after Boehringer blocking (with triton), followed by goat-antirabbit biotin (both obtained from DakoCytomation, Heverlee, Belgium). Slides were then incubated with streptavidin alkaline phosphatase (DakoCytomation) and coloured with Vector blue (Vector Laboratories, Inc., Burlingame, CA, USA). Apoptotic type II epithelial cells were identified by their condensed and intensively brown cell nuclei (TUNEL positive) and deep blue-coloured granules in their cytoplasm (proSPC positive). Double-positive cells were counted on 10 random lung fields, captured at a $\times 400$ magnification, using a Zeiss KS400 image analyser platform, and results were expressed as cell counts relative to image surface $\left(\mathrm{mm}^{2}\right)$.

\section{ELISA protein measurements}

At 6 months, soluble TNF- $\alpha$ R1 and TNF- $\alpha$ R2 protein levels were determined in BAL using a commercially available ELISA kit (R\&D Systems Europe, Abingdon, UK).

\section{Semiquantitative RT-PCR analysis}

In the third experiment (4.5 months' CS exposure), total lung RNA was extracted using the RNeasy Midi kit (Qiagen, Hilden, Germany), with an additional DNAse step. Reverse transcription was performed at $48^{\circ} \mathrm{C}$ for $30 \mathrm{~min}$, followed by a 12-min incubation at $95^{\circ} \mathrm{C}$ for denaturation of RNA-DNA heteroduplexes, and a DNA-amplification with 50 cycles. RTPCR was performed starting from $10 \mathrm{ng}$ of total RNA, using an ABI PRISM 7700 Sequence Detection System (Applied Biosystems, Foster City, CA, USA). Expression of matrix metalloproteinase (MMP)-12 mRNA relative to hypoxanthine guanine phophoribosyl transferase mRNA, was analysed with the Assays-on-Demand ${ }^{\mathrm{TM}}$ Gene Expression Products (Applied Biosystems).

\section{Statistical analysis}

Reported values are expressed as mean \pm SEM. Statistical analysis was performed using nonparametric tests (KruskallWallis, Mann-Whitney U-test), and p-values $<0.05$ were considered as significant.

\section{RESULTS}

\section{Inflammatory changes in BAL fluid}

At 3 and 6 months, the CS-exposed WT, TNF- $\alpha$ R1 KO and $\mathrm{TNF} \alpha \mathrm{R} 2 \mathrm{KO}$ mice developed, in comparison with air-exposed mice, an inflammatory cell influx in the BAL fluid (BALF). Increased amounts of DCs, macrophages, neutrophils and lymphocytes were recovered by BAL in CS-exposed, TNF $\alpha$ R2 $\mathrm{KO}$ and WT mice, compared with air-exposed littermates $(\mathrm{p}<0.05$ for all cell types; fig. 1). However, the CS-induced increase in total cells, DCs, macrophages, neutrophils and lymphocytes was significantly attenuated in TNF $\alpha$ R2 KO mice compared with WT mice at 3 months ( $p<0.05$ for all cell types). In BALF of TNF- $\alpha$ R1 KO mice, DCs and neutrophil numbers tended to be lower in contrast to WT mice after a 3-month exposure to CS. After longer exposure time (6 months), the increase in DCs and neutrophils in the CS-exposed TNF- $\alpha$ R2 $\mathrm{KO}$ mice was still smaller than in the smoke-exposed WT and TNF- $\alpha$ R1 KO mice, but this difference did not reach statistical significance $(\mathrm{p}=0.056$ for DCs and $\mathrm{p}=0.095$ for neutrophils in BALF of TNF- $\alpha$ R2 KO versus WT mice exposed to CS for 6 months; fig. 1a and c). No differences were observed between the macrophage and lymphocyte numbers found in the BALFs taken from TNF $\alpha$ R2 KO and WT mice exposed to CS for 6 months (fig. $1 \mathrm{~b}$ and d). Eosinophil numbers in BAL were small in all groups and did not change significantly upon exposure to CS (data not shown).

\section{Inflammatory changes in the lungs}

CS induced a significant increase in DC numbers and both total and activated CD4+ and CD8+ T-lymphocytes in lung tissue after 3 and 6 months compared with air-exposed mice $(\mathrm{p}<0.05$ for all cell types; fig. 2). 

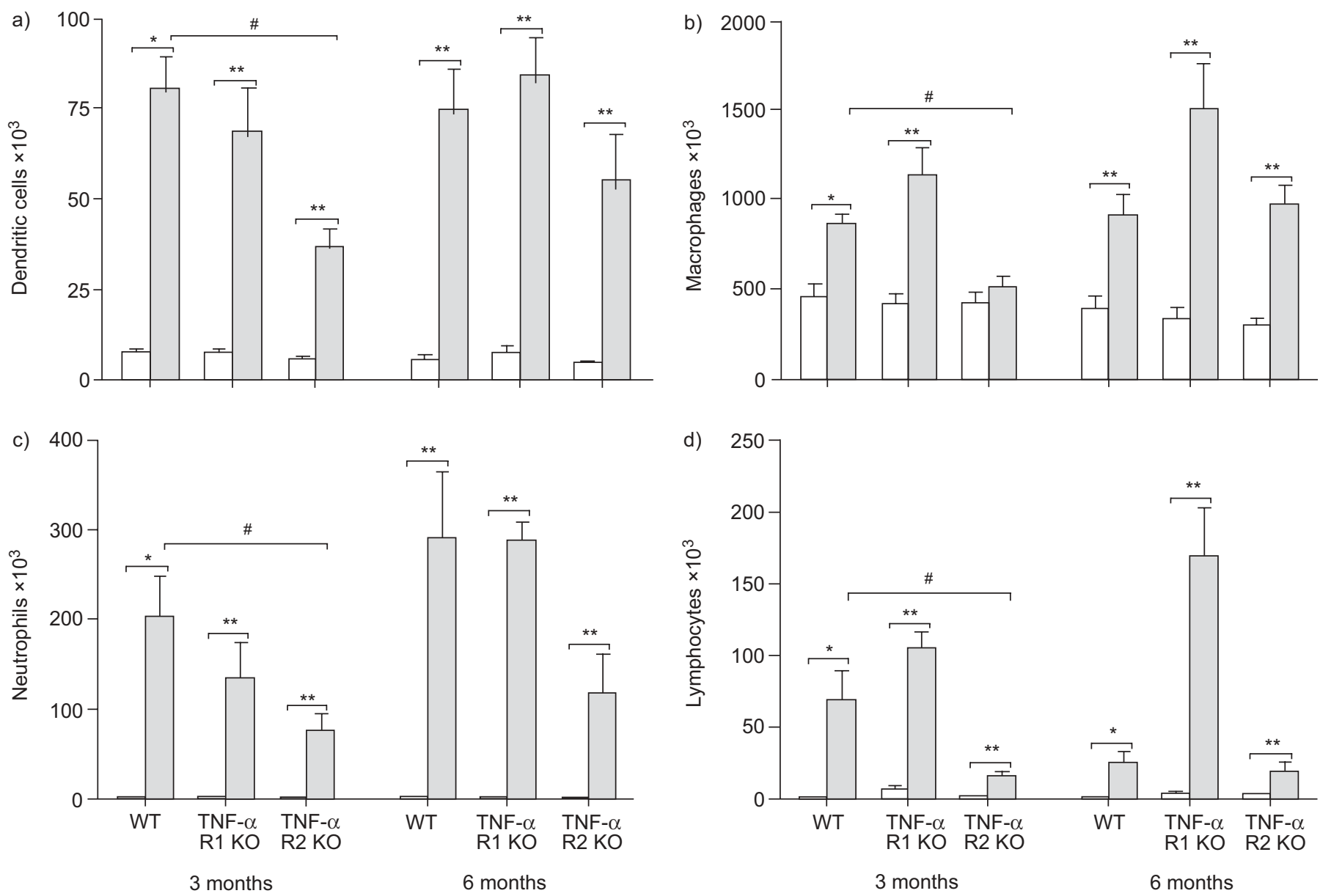

FIGURE 1. Effect of exposure to cigarette smoke (CS; $\square$ ) and air ( $\square$ ) during a 3- or 6-month period on a) dendritic cells, b) macrophages, c) neutrophils and d) lymphocytes in bronchoalveolar lavage fluid (absolute numbers) in wild type (WT) mice, tumour necrosis factor (TNF)- $\alpha$ receptor p55 (R1) knockout (KO) mice and TNF- $\alpha$ receptor p75 (R2) KO mice. Results are expressed as mean \pm SEM. *: $p<0.05$ for CS-exposed mice versus air-exposed mice at the corresponding time point; **: $p<0.01$ for CS-exposed mice versus air-exposed mice at the corresponding time point; ${ }^{*}: p<0.05$ for TNF- $\alpha$ R2 KO mice versus WT mice at the corresponding time point.

CS induced a similar increase in DCs in TNF- $\alpha$ R1 KO, TNF- $\alpha$ $\mathrm{R} 2 \mathrm{KO}$ and $\mathrm{WT}$ mice at both time points. In the lungs, no differences in the number of CD4+ and CD8+ lymphocytes were observed between CS-exposed TNF- $\alpha$ R KO mice and WT mice. However, the expression of the activation marker CD69 on CD4+ and CD8+ T-cells tended to be lower in CS- and airexposed TNF- $\alpha$ R2 KO mice compared with WT mice (fig. 2).

\section{CS induces pulmonary emphysema in WT and TNF- $\alpha$ R1 KO mice in contrast with TNF- $\alpha$ R2 KO mice}

The DI was measured to evaluate the destruction of alveolar walls and the Lm was calculated to examine the enlargement of alveolar spaces.

Exposure to CS significantly and progressively induced airspace enlargement in WT and TNF- $\alpha$ R1 KO mice after 3 and 6 months. In contrast, airspace enlargement was not observed in TNF- $\alpha$ R2 KO mice, since Lm did not change significantly in TNF- $\alpha$ R2 KO mice upon being exposed to CS $(\mathrm{p}=0.7$; table 1 ; fig. 3$)$.

CS clearly induced alveolar wall destruction (as shown by an increase of the DI) by 44.8 and $33.1 \%$ in the WT and TNF- $\alpha$ R1
KO mice, respectively (table 1 ). However, no alveolar wall destruction was induced in TNF $\alpha$ R2 KO mice upon exposure to CS $(\mathrm{p}=0.4$; table 1$)$.

\section{Apoptosis in lungs of CS-exposed TNF- $\alpha$ R2 KO mice compared with WT mice}

It has been demonstrated that alveolar wall apoptosis can cause emphysema in mice [30]. Since the current authors observed a significant protection against emphysema in TNF- $\alpha$ $\mathrm{R} 2 \mathrm{KO}$ mice exposed to CS, the apoptosis of type II alveolar epithelial cells was evaluated using TUNEL/proSPC double staining (figs. 4 and 5). CS exposure induced a clear increase of apoptotic type II epithelial cells in lung tissue of WT mice compared with air-exposed littermates $(p<0.05)$. The CSinduced increase in the number of apoptotic type II pneumocytes attenuated in TNF- $\alpha$ R1 KO mice. Moreover, no differences in the number of apoptotic type II pneumocytes were observed in air and CS exposed TNF- $\alpha$ R2 KO mice. TUNEL/proSPC double-stained lung tissue sections from WT, TNF- $\alpha$ R1 KO and TNF- $\alpha$ R2 KO mice are demonstrated in figure 4 . 

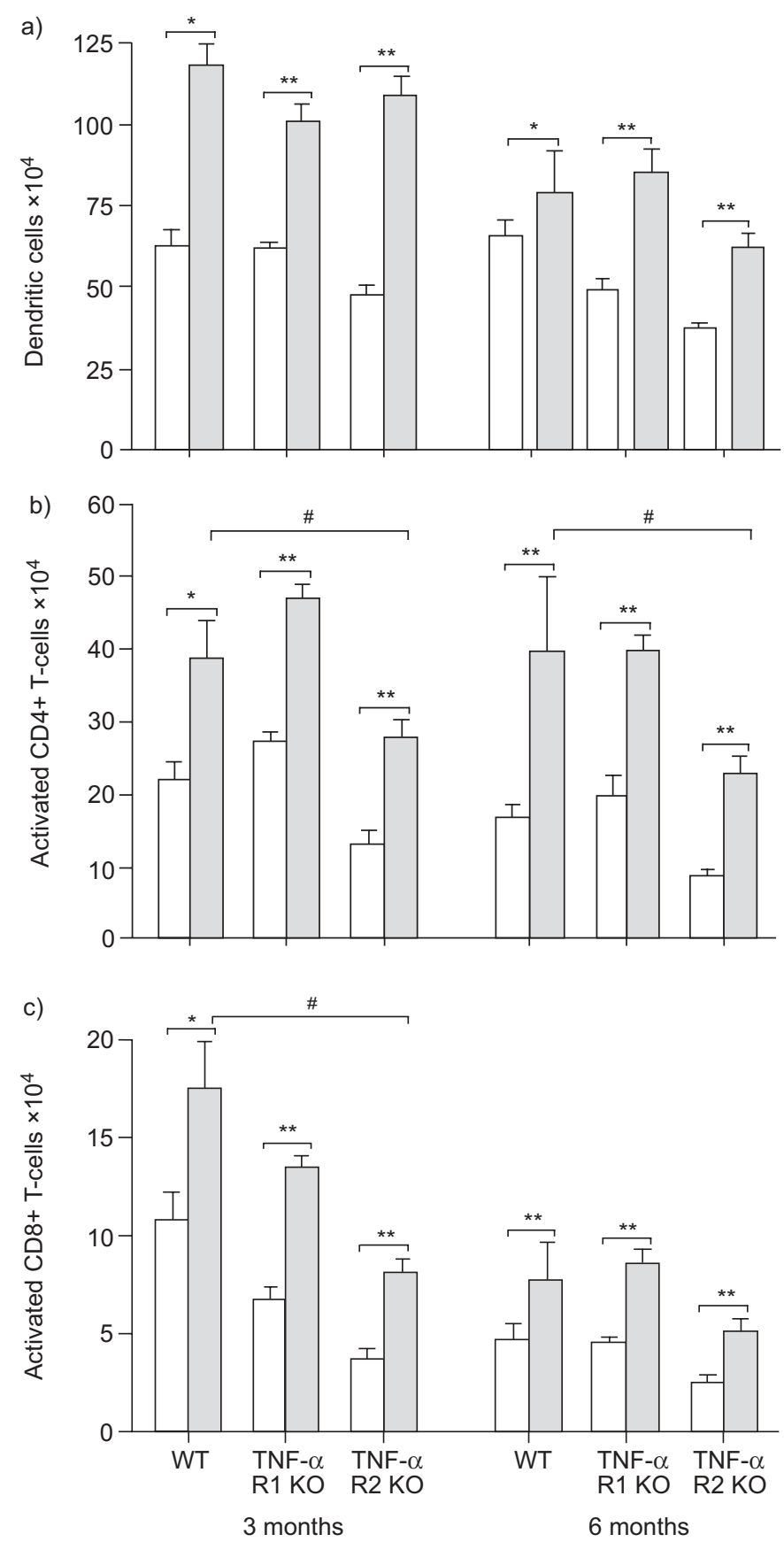

FIGURE 2. Effect of exposure to cigarette smoke (CS; $\left.-{ }^{-}\right)$and air ( $\square$ ) exposure during a 3- or 6-month period on a) dendritic cell, b) activated CD4+ T-cell and c) CD8+ T-cell populations in the lungs of wild type (WT) mice, tumour necrosis factor (TNF)- $\alpha$ receptor p55 (R1) knock out (KO) mice and TNF- $\alpha$ receptor p75 (R2) KO mice, as determined by flow cytometry. Results are expressed as mean \pm SEM. *: $p<0.05$ for CS-exposed mice versus air-exposed mice at the corresponding time point; ${ }^{*}$ : $p<0.01$ for CS-exposed mice versus air-exposed mice at the corresponding time point; $\#: p=0.099^{\circ}: p=0.056$ for specific KO mice versus WT mice at the corresponding time point.

\section{CS exposure increases soluble TNF- $\alpha$ R1 and TNF- $\alpha$ R2 in the BALF of mice}

Since COPD patients have elevated levels of both soluble TNF$\alpha$ receptors in sputum and serum [23], the current authors were

\begin{tabular}{|c|c|c|c|c|c|c|}
\hline \multirow[t]{4}{*}{ TABLE } & \multicolumn{6}{|c|}{$\begin{array}{l}\text { Quantification of emphysema by mean linear } \\
\text { intercept and destructive index upon exposure to } \\
\text { cigarette smoke (CS) and air }\end{array}$} \\
\hline & \multicolumn{4}{|c|}{ Mean linear intercept $\mu \mathrm{m}$} & \multirow{2}{*}{\multicolumn{2}{|c|}{$\frac{\text { Destructive index }}{6 \text { months }}$}} \\
\hline & \multicolumn{2}{|c|}{3 months } & \multicolumn{2}{|c|}{6 months } & & \\
\hline & Air & cs & Air & cs & Air & cs \\
\hline WT & $39.1 \pm 0.3$ & $41.0 \pm 0.2^{*}$ & $38.1 \pm 0.5$ & $43.1 \pm 0.2^{*}$ & $24.1 \pm 0.9$ & $34.9 \pm 0.7^{*}$ \\
\hline $\begin{array}{l}\text { TNF- } \alpha \\
\text { R1 KO }\end{array}$ & $39.1 \pm 0.1$ & $41.6 \pm 0.1^{*}$ & $38.0 \pm 0.1$ & $42.5 \pm 0.4^{*}$ & $23.9 \pm 0.2$ & $31.8 \pm 0.8^{*}$ \\
\hline $\begin{array}{l}\text { TNF- } \alpha \\
\text { R2 KO }\end{array}$ & $38.3 \pm 0.2$ & $38.6 \pm 0.2^{\#}$ & $38.5 \pm 0.2$ & $38.1 \pm 0.2^{\#}$ & $27.2 \pm 0.6$ & $27.6 \pm 0.3^{\#}$ \\
\hline $\begin{array}{l}\text { Data are } \\
\text { necrosis } f \\
\text { factor- } \alpha \text { r } \\
\#: p<0.0\end{array}$ & $\begin{array}{l}\text { presented } \\
\text { factor- } \alpha \text { rece } \\
\text { eceptor p7 } \\
5 \text { versus WT }\end{array}$ & $\begin{array}{l}\text { as mean } \pm s \\
\text { eptor p55 knc } \\
5 \text { knockout } \\
\text { and } \mathrm{R} 1 \mathrm{KO}\end{array}$ & $\begin{array}{l}\text { EM. WT: wil } \\
\text { ckout mice } \\
\text { nice. }{ }^{*}: \mathrm{p} \\
\text { mice. }\end{array}$ & $\begin{array}{l}\text { ild type; TN } \\
<0.05 \text { verse }\end{array}$ & $\begin{array}{l}\mathrm{NF}-\alpha \mathrm{R} 1 \mathrm{KC} \\
\mathrm{KO} \text { : tumou } \\
\text { us air-expos }\end{array}$ & $\begin{array}{l}\text { O: tumour } \\
\text { ur necrosis } \\
\text { sed mice; }\end{array}$ \\
\hline
\end{tabular}

interested in the protein levels of TNF- $\alpha$ R 1 and TNF- $\alpha$ R2 in the airways and lungs in this murine model of COPD. The basal protein levels of soluble TNF- $\alpha$ R2 (sTNF- $\alpha$ R2) were six times higher than the levels of sTNF- $\alpha$ R1 in the BALF of WT mice. CS exposure induced an increase of the protein levels of sTNF- $\alpha$ R1 and sTNF- $\alpha$ R2 in the BALF of WT animals at 6 months. Interestingly, the relative increase of sTNF- $\alpha$ R2 is higher (10-fold) compared with sTNF- $\alpha$ R1 (four-fold, fig. 6).

CS exposure increases MMP-12 mRNA in the lungs of mice In order to elucidate the possible mechanisms by which pulmonary emphysema develops in CS-exposed mice, mRNA levels of MMP-12 were measured in the lungs of air- and CSexposed mice by RT-PCR. Exposure to CS for 4.5 months increased the lung mRNA expression of MMP-12 in WT, TNF- $\alpha$ $\mathrm{R} 1 \mathrm{KO}$ and TNF- $\alpha$ R2 KO mice compared with air-exposed littermates (fig. 7).

\section{Lack of weight gain in CS-exposed WT and TNF- $\alpha$ R1 KO mice in contrast with TNF- $\alpha$ R2 KO mice}

After 3, 4.5 and 6 months of CS exposure, a significant failure to gain weight was observed in WT and TNF- $\alpha$ R1 KO mice (table 2). In contrast, a similar increase in body weight was observed in air- and CS- exposed TNF- $\alpha$ R2 KO mice. A significant negative correlation was observed between body weight and mean linear intercept $(r=-0.468, p<0.01)$. Due to the intriguing lack of weight gain, a third experiment was performed, in which WT, TNF- $\alpha$ R1 KO and TNF- $\alpha$ R2 KO mice were exposed to CS for 4.5 months. In order to study the kinetics of body weight, the body weight of the mice was examined on a weekly basis. WT, TNF- $\alpha$ R1 KO and TNF- $\alpha$ R2 $\mathrm{KO}$ mice clearly gained weight during 4.5 months of air exposure. Significantly smaller increases in weight were observed in CS-exposed WT and TNF- $\alpha$ R1 KO animals versus air-exposed littermates. In contrast, CS-exposed TNF- $\alpha$ R2 KO mice had similar increases in weight as air-exposed TNF- $\alpha$ R2 $\mathrm{KO}$ mice (fig. 8). Both adipose tissue and skeletal muscle may be involved in weight gain or loss. To further investigate if muscle wasting (atrophy) could contribute to the observed 

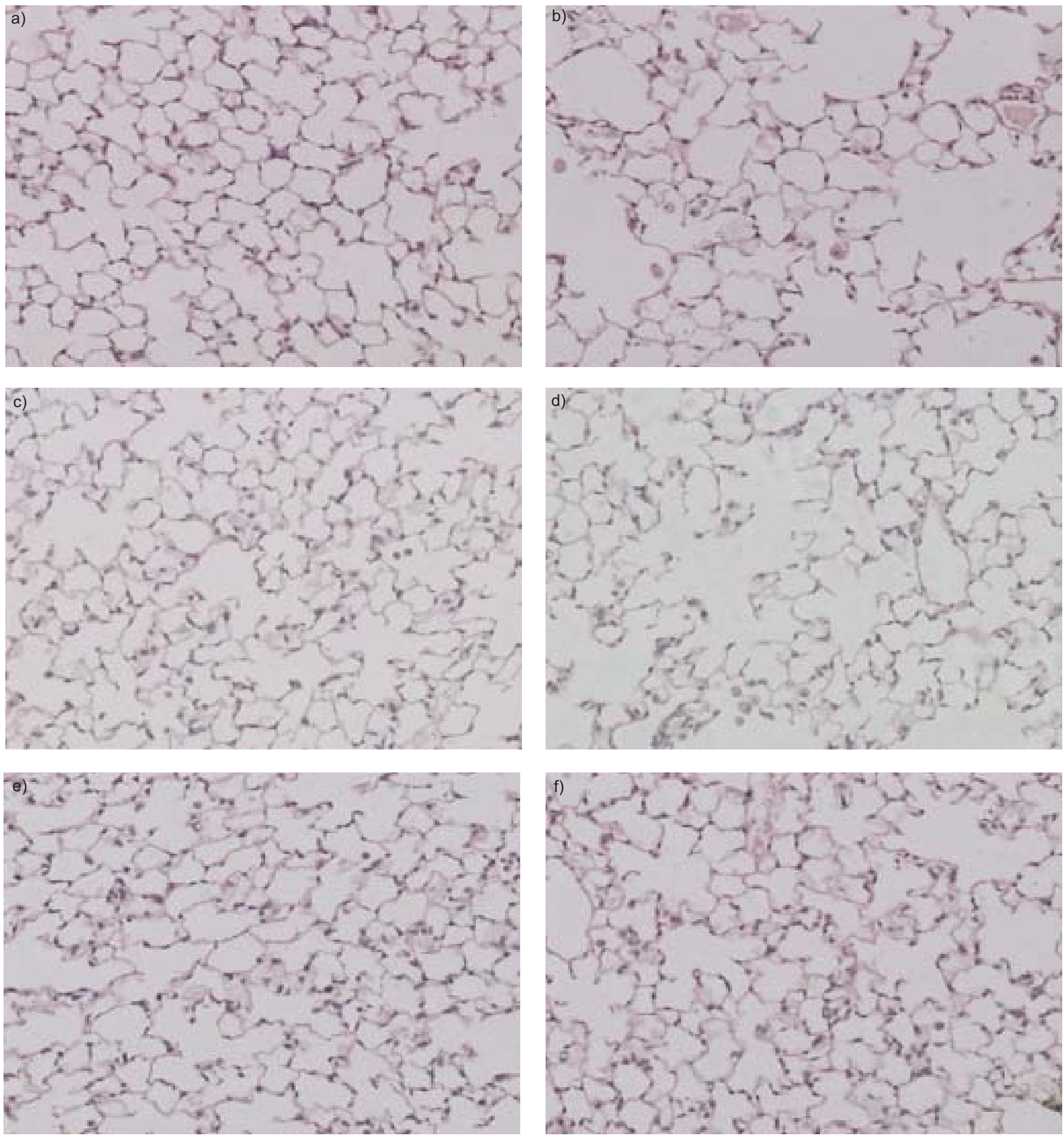

FIGURE 3. Photomicrographs of haematoxylin and eosin-stained lung tissue of: wild type mice exposed to air (a) and to cigarette smoke (CS; b); tumour necrosis factor (TNF)- $\alpha$ receptor p55 (R1) knockout (KO) mice exposed to air (c) and CS (d); and TNF- $\alpha$ receptor p75 (R2) KO mice exposed to air (e) and CS (f) for 6 months.

failure to gain weight, the weight of several muscles of the hind limb was evaluated. The weight of the gastrocnemius was similar in air-exposed and CS-exposed TNF- $\alpha$ R2 KO mice, while significant loss of muscle mass was observed in CSexposed WT and TNF- $\alpha$ R1 KO mice compared with their airexposed littermates (data not shown).

\section{DISCUSSION}

In this murine model of COPD [26], the current authors demonstrated that both soluble TNF- $\alpha$ receptors are induced in the BALF of WT mice upon exposure to CS and that the relative increase of sTNF- $\alpha$ R2 is higher compared with sTNF- $\alpha$ R1. CS exposure caused airway and lung inflammation in 

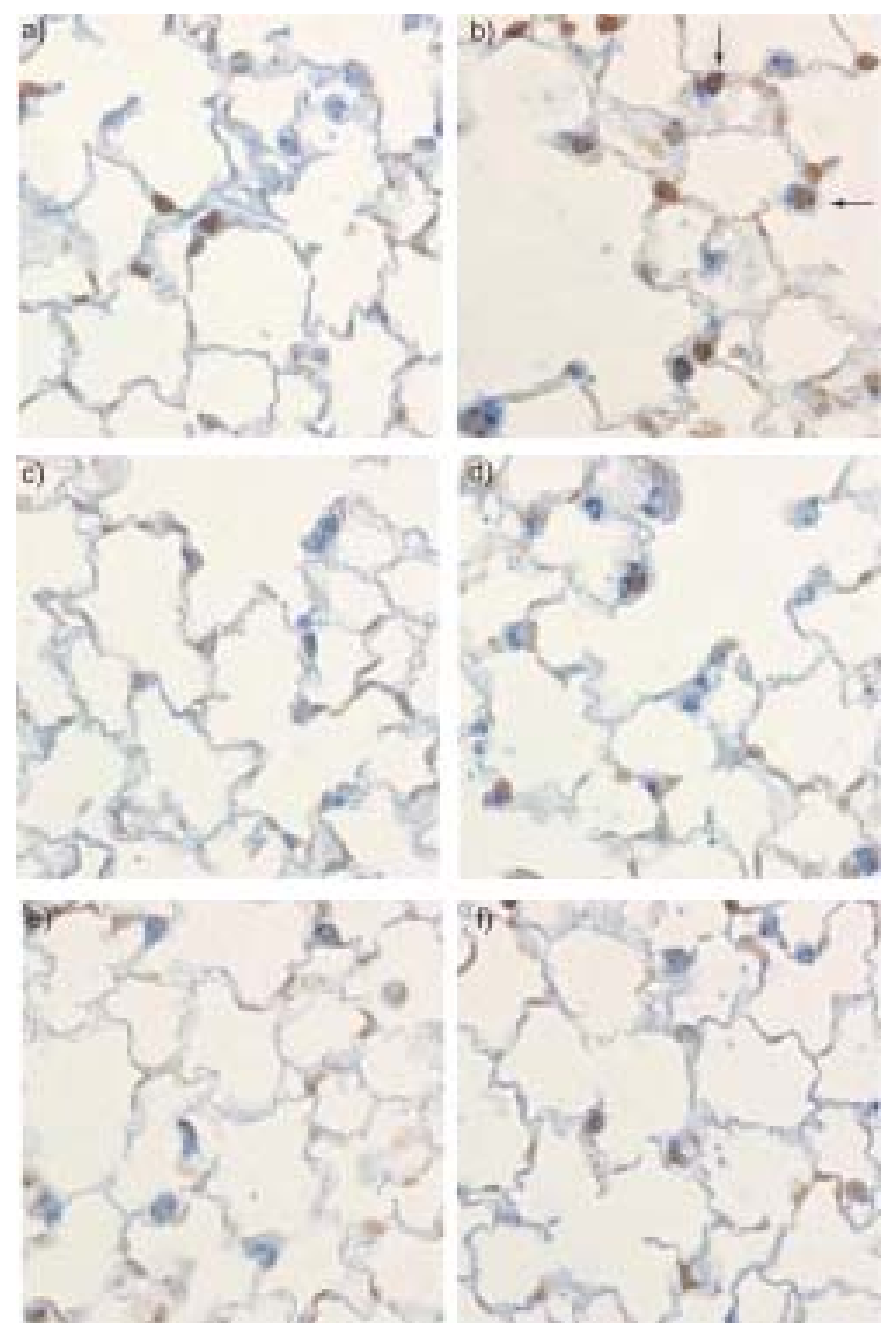

FIGURE 4. Apoptotic type $\|$ alveolar epithelial cells, detected by terminal deoxynucleotidyltransferase-mediated deoxyuridine triphosphate nick-end labelling (TUNEL)/ prosurfactant protein C (proSPC) double staining, in the lungs of: wild type mice exposed to air (a) and cigarette smoke (CS; b), tumour necrosis factor (TNF)- $\alpha$ receptor p55 knockout (KO) mice exposed to air (c) and CS (d), and TNF- $\alpha$ receptor p75 KO mice exposed to air (e) and CS (f) for 6 months. Apoptotic type II pneumocytes were identified by their condensed and intensively brown cell nuclei (TUNEL positive) and deep blue-coloured granules in their cytoplasm (proSPC positive, as indicated by arrows).

TNF- $\alpha$ R1 KO, TNF- $\alpha$ R2 KO and WT mice. However, in TNF- $\alpha$ R2 KO mice, the CS-induced influx of DCs, neutrophils, macrophages and lymphocytes in BALF was clearly attenuated, as well as the smoke-induced infiltration of activated Tlymphocytes in lungs after 3 months. Most importantly, no emphysema was observed in CS-exposed TNF- $\alpha$ R2 KO mice compared with WT and TNF- $\alpha$ R1 KO mice. Finally, the increase of body weight in CS-exposed WT and TNF- $\alpha$ R1 KO mice was small in contrast with the increase of body weight in TNF- $\alpha$ R2 KO animals. The current data indicate that both TNF- $\alpha$ receptors are involved in CS-induced inflammation and the development of emphysema, but TNF- $\alpha$ R2 is the most active receptor.

Multiple studies of lung specimens, bronchial biopsies and BALF of patients with COPD have demonstrated that the

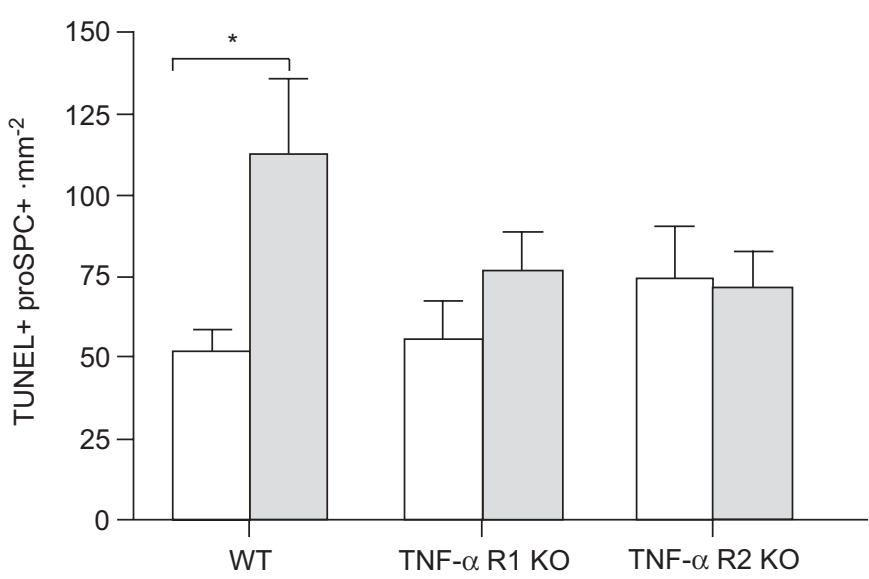

FIGURE 5. Effect of cigarette smoke (CS) exposure for 6 months on apoptotic type II alveolar epithelial cells of wild type (WT), tumour necrosis factor (TNF)- $\alpha$ receptor p55 (R1) knockout (KO) and TNF- $\alpha$ receptor p75 (R2) KO mice. TUNEL: terminal deoxynucleotidyltransferase-mediated deoxyuridine triphosphate nick-end labelling; proSPC: prosurfactant protein C. $\square$ : air-exposed mice; $\mathbf{\square}$ : CS-exposed mice. ${ }^{*}: p<0.05$
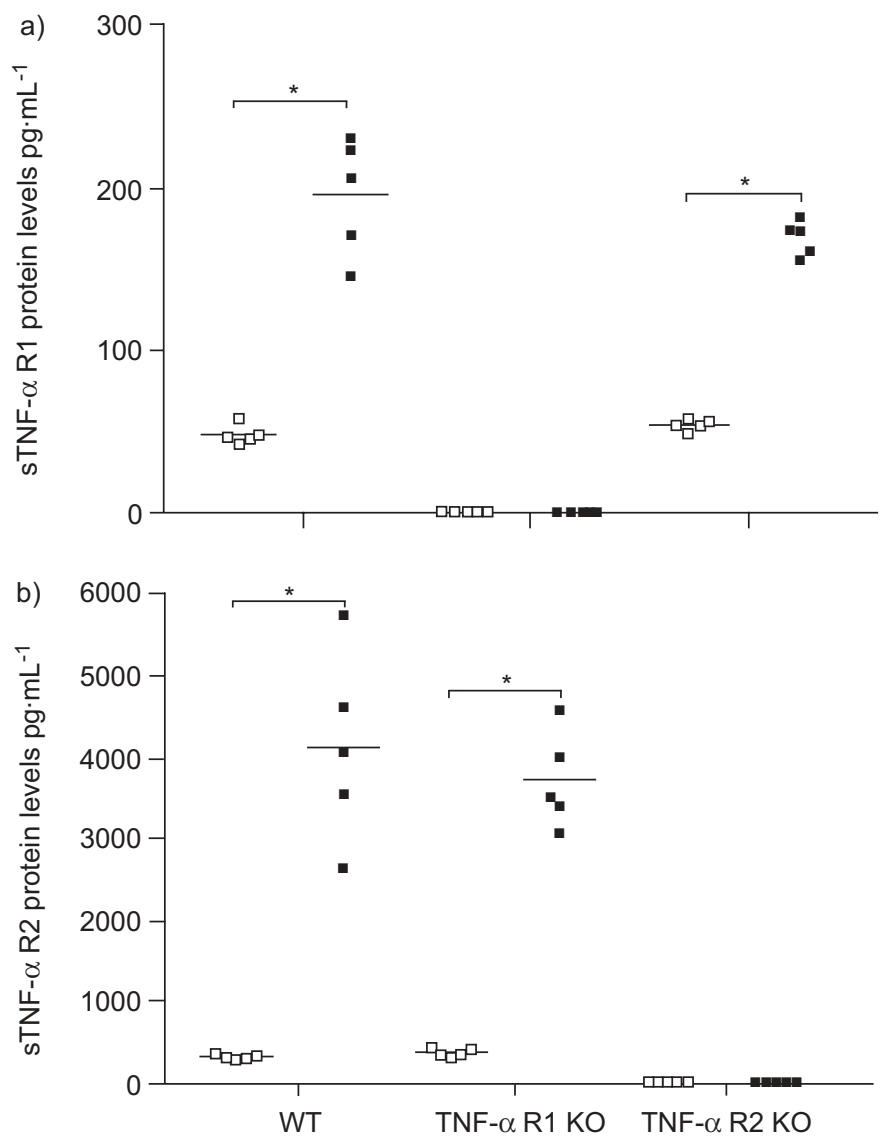

FIGURE 6. Effect of cigarette smoke (CS) exposure for 6 months on the protein levels of a) soluble tumour necrosis factor (STNF)- $\alpha$ receptor p55 (R1) and b) STNF- $\alpha$ receptor p75 (R2) in bronchoalveolar lavage fluid of wild type (WT), TNF- $\alpha$ R1 knockout (KO) and TNF- $\alpha$ R2 KO mice. $\square$ : air-exposed mice; $\mathbf{a}$ : CS-exposed mice; — : mean. ${ }^{*}$ : $p<0.05$. 


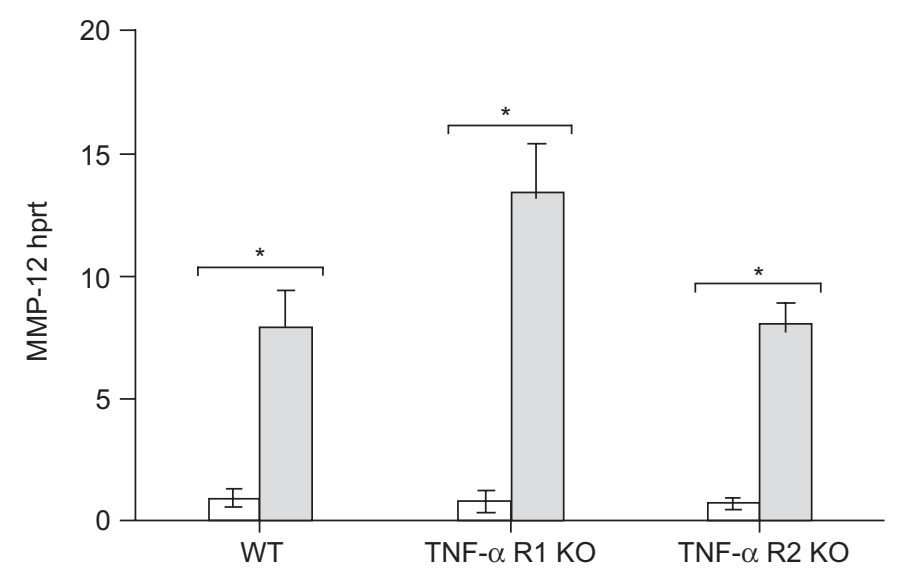

FIGURE 7. Matrix metalloproteinase (MMP)-12 mRNA expression in lung tissue of wild type (WT), tumour necrosis factor (TNF)- $\alpha$ receptor p55 (R1) knockout (KO) and TNF- $\alpha$ receptor p75 (R2) KO mice after 4.5 months of cigarette smoke ( $\square$ ) and air ( $\square$ ) exposure. RT-PCR results are expressed as a ratio of MMP-12 mRNA with hypoxanthine guanine phosphoribosyl transferase (hprt) mRNA. Data are presented as mean \pm SEM. $n=8$ mice per group. ${ }^{*}: p<0.05$.

chronic pulmonary inflammation in COPD is characterised by the increased numbers of inflammatory cells of both the innate immune system (macrophages and neutrophils), as well as the acquired immune system (B- and T-lymphocytes) [31, 32]. The present study demonstrated CS-induced inflammation in the airways and lungs of WT, TNF- $\alpha$ R1 KO and TNF- $\alpha$ R2 KO animals, indicating that both TNF- $\alpha$ receptors are involved in the TNF- $\alpha$-mediated recruitment of inflammatory cells [7, 24]. However, the very high levels of sTNF- $\alpha$ R2 in BALF of CSexposed WT animals and the attenuated pulmonary inflammation in CS-exposed TNF- $\alpha$ R2 KO mice suggest that the TNF- $\alpha$ R2 is the most active receptor in the TNF- $\alpha$-mediated local inflammatory response in mice upon exposure to CS. Whereas most of the biological effects induced by TNF- $\alpha$ have been attributed to TNF- $\alpha$ R1, TNF- $\alpha$ R2 has been reported to stimulate TNF- $\alpha$-induced T-cell proliferation [33]. The present observations of a reduced activation of T-lymphocytes in the

\begin{tabular}{|c|c|c|c|c|c|c|}
\hline \multirow[t]{4}{*}{ TABLE } & \multicolumn{6}{|c|}{$\begin{array}{l}\text { Final body mass after } 3-, 4.5 \text { - or } 6 \text {-month } \\
\text { exposure to air or cigarette smoke (CS) by the } \\
\text { different types of mice }\end{array}$} \\
\hline & \multicolumn{6}{|c|}{ Months } \\
\hline & \multicolumn{2}{|c|}{3} & \multicolumn{2}{|c|}{4.5} & \multicolumn{2}{|c|}{6} \\
\hline & Air & CS & Air & CS & Air & CS \\
\hline WT & $31.3 \pm 0.3$ & $27.9 \pm 0.8^{\star}$ & $32.3 \pm 0.6$ & $26.1 \pm 0.4^{*}$ & $35.1 \pm 0.4$ & $28.9 \pm 0.6^{*}$ \\
\hline $\begin{array}{l}\text { TNF- } \alpha \\
\text { R1 KO }\end{array}$ & $30.1 \pm 1.0$ & $26.9 \pm 0.6^{*}$ & $31.7 \pm 0.5$ & $27.1 \pm 0.4^{\star}$ & $36.9 \pm 2.3$ & $29.9 \pm 0.3^{*}$ \\
\hline $\begin{array}{l}\text { TNF- } \alpha \\
\text { R2 KO }\end{array}$ & $31.5 \pm 0.7$ & $30.0 \pm 1.0$ & $32.8 \pm 0.9$ & $30.0 \pm 0.6$ & $33.9 \pm 1.9$ & $32.5 \pm 0.3$ \\
\hline
\end{tabular}

Data are presented as mean \pm SEM. WT: wild type; TNF- $\alpha$ R1 KO: tumour necrosis factor- $\alpha$ receptor p55 knockout mice; TNF- $\alpha$ R2 KO: : tumour necrosis factor- $\alpha$ receptor $p 75$ knockout mice. ${ }^{*}: p<0.05$ versus air-exposed mice.
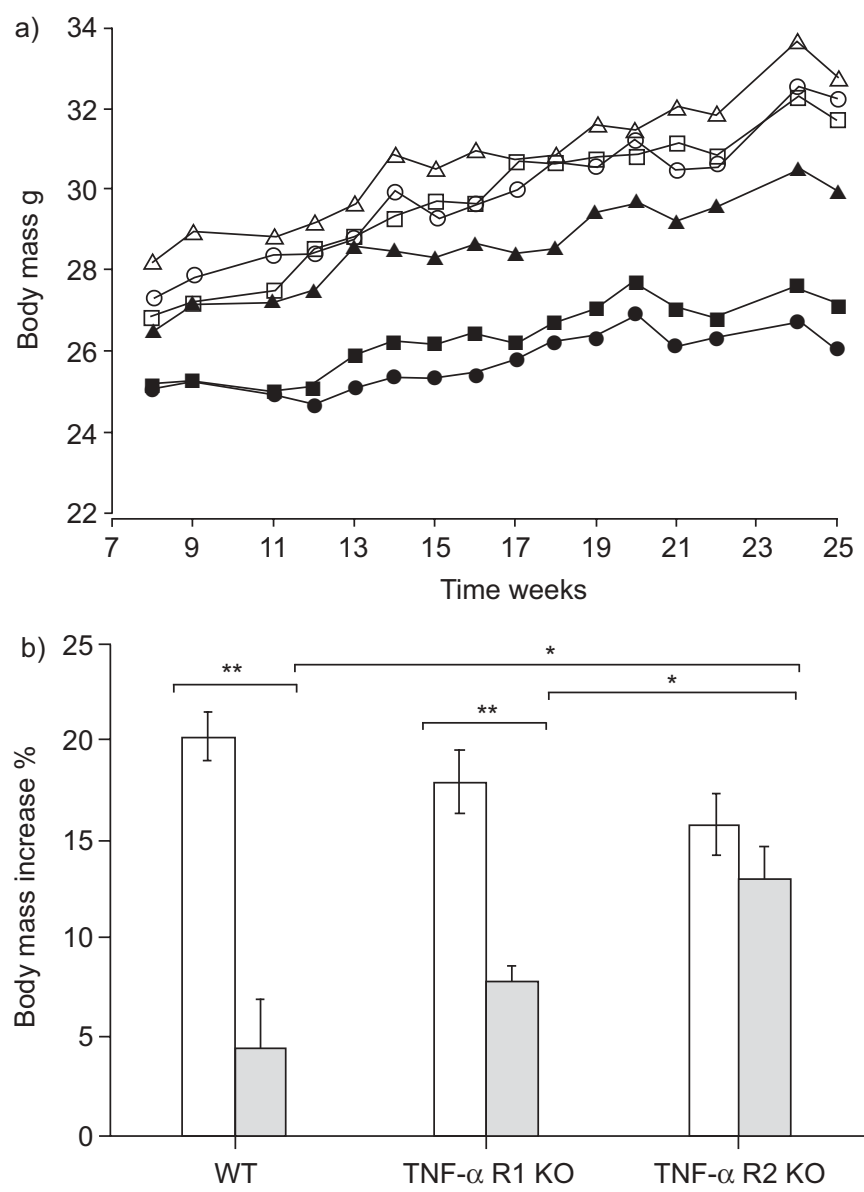

FIGURE 8. Effect of cigarette smoke (CS) exposure for 4.5 months on body mass of wild type (WT), tumour necrosis factor (TNF)- $\alpha$ receptor p55 (R1) knockout (KO) and TNF- $\alpha$ receptor p75 (R2) KO mice. a) Body mass kinetics. $\bigcirc$ : air-exposed WT; - CS-exposed WT; $\square$ : air-exposed TNF- $\alpha$ R1 KO; $\mathbf{\square}$ : CS-exposed TNF- $\alpha$ R1 $\mathrm{KO} ; \triangle$ : air-exposed TNF- $\alpha$ R2 KO; $\mathbf{\Delta}$ : CS-exposed TNF- $\alpha$ R2 KO. b) Percentage body mass increase: relative increase in body mass after 4.5 months' exposure to air or CS compared with baseline body mass at the start of the experiment, i.e. at 8 weeks of age. $\square$ : air-exposed mice; $\mathbf{\square}$ : CS-exposed mice. ${ }^{*}: p<0.05$; ${ }^{*}: p<0.01$.

lungs of mice lacking TNF- $\alpha$ R2 and the high lymphocyte numbers in BALF of TNF- $\alpha$ R1 KO mice, expressing exclusively the TNF- $\alpha$ R2, further underline the importance of the $\mathrm{R} 2$ receptor in $\mathrm{T}$-cell proliferation.

Furthermore, the current authors demonstrated an impaired accumulation of DCs, antigen-presenting cells originating from monocyte precursors in the bone marrow [34, 35], in the airways of CS-exposed TNF- $\alpha$ R2 KO mice, but not in TNF- $\alpha$ R1 KO mice, emphasising the importance of TNF- $\alpha$ R2 in TNF$\alpha$-mediated DC accumulation. A similar observation was made by WANG et al. [36], who observed a reduced Langerhans cell (antigen-presenting cell in the skin, belonging to the DC family) migration in mice lacking TNF- $\alpha$ R2. TNF- $\alpha$ strongly stimulates DC migration and maturation [37]. Interestingly, TNF- $\alpha$ R2 is now being recognised as the major TNF- $\alpha$ receptor type expressed by monocytes (precursors of DC) [38] and this could explain the reduced influx of DCs in TNF $\alpha$ R2 KO mice exposed to CS. 
Emphysema is an important structural disorder in COPD patients, characterised by destruction of the alveolar walls, leading to the enlargement of airspaces. At 6 months, CS exposure induced emphysema, as evidenced by an increase in DI of $44.8 \%$ in WT mice, $33.1 \%$ in TNF- $\alpha$ R1 KO mice and only $1.8 \%$ in TNF- $\alpha$ R2 KO mice. These data indicate that both receptors may contribute to emphysema, but the contribution of TNF- $\alpha$ R2 is the most prominent. Several mechanisms might explain why TNF- $\alpha$ R2 KO mice appear to be protected against pulmonary emphysema after chronic CS exposure. First, inflammatory cells might contribute to the development of pulmonary emphysema, since they have the capacity to secrete many elastolytic enzymes, such as neutrophil elastase (by neutrophils) and MMP-12 (by macrophages and DCs) [31, 39, 40]. As discussed above, inflammatory cells in the airways of CS-exposed TNF- $\alpha$ R2 KO animals were attenuated compared with CS-exposed WT mice and this may result in decreased amounts of proteolytic enzymes, thereby dampening any ensuing lung tissue destruction. However, the CS-induced expression of MMP-12 lung mRNA was similar in WT and TNF- $\alpha$ R2 KO mice, indicating that inflammation, accompanied by the release of proteolytic enzymes, can only partially explain the protection of the TNF- $\alpha \mathrm{R} 2 \mathrm{KO}$ mice against emphysema. Secondly, it has been demonstrated that alveolar wall apoptosis can cause emphysematous changes in mice as well as in humans $[30,41]$. Although there are several receptormediated pathways of apoptosis, CS and oxidative stress might engage apoptosis of alveolar epithelial cells by death receptor pathways, including TNF- $\alpha$ receptor signalling [42]. Exposure to CS significantly increased the number of apoptotic type II pneumocytes in WT mice, whereas the number of apoptotic type II alveolar epithelial cells was only slightly increased in TNF- $\alpha$ R1 KO mice and not affected at all in TNF- $\alpha$ $\mathrm{R} 2 \mathrm{KO}$ mice. These results further underline the importance of both TNF- $\alpha$ receptors in apoptosis. Moreover, the findings in this murine model of COPD suggest a TNF- $\alpha$ R2-mediated alveolar wall apoptosis, which may cause emphysema. Finally, besides chronic inflammation and apoptosis, other mechanisms, such as oxidative stress that occurs when reactive oxygen species (ROS) are produced in excess of antioxidantia, may play important roles in the development of emphysema. CS itself contains high concentrations of ROS, resulting in amplification and activation of the inflammatory cells, which also generate ROS leading to a vicious circle. Interestingly, a recent study demonstrated that oxidative stress also regulates apoptosis and this was independent of TNF- $\alpha$ R1 [43].

Although COPD is characterised by chronic inflammation of the small airways, it is becoming clear that patients with COPD also have systemic manifestations that are not reflected by pulmonary function tests. Indeed, COPD can have many diverse extrapulmonary effects, including osteoporosis, skeletal muscle wasting, nutritional abnormalities and weight loss (cachexia) [44]. Moreover, the body mass index (BMI) appears to be an independent risk factor of death in patients with COPD, since there is an inverse relationship between BMI and survival $[45,46]$. The pathogenesis of weight loss in COPD is incompletely understood, but several studies report a clear correlation between weight loss and elevated TNF- $\alpha$ (cachectin) levels in serum of patients with severe COPD [14]. TNF- $\alpha$ R2 may be involved in the failure of weight gain in CS-exposed mice, since the current authors observed similar increases in weight in air- and CS- exposed TNF- $\alpha$ R2 KO mice, while a failure of weight gain was observed in WT and TNF- $\alpha$ R1 KO mice exposed to smoke. It is obvious that the smaller increases in weight in WT and TNF- $\alpha$ R1 KO mice were already visible in the first few weeks, while no emphysema has been observed following exposure to CS for 1 month (current authors' observations and [47]). In contrast to humans where weight loss, which occurrs in a subgroup of patients who develop severe COPD and emphysema, is a late phenomenon related to systemic effects of the disease, the early alterations of body weight in this mouse model of COPD seem to be due to an acute effect of cigarette smoking. Several components of CS, in particular nicotine, may be responsible for the lack of weight gain in smoking mice [48]. Both skeletal muscle and adipose tissue may be involved in weight loss of COPD patients and it has been suggested that loss of skeletal muscle mass is the main cause, whereas loss of fat mass contributes to a lesser extent [49]. The current authors observed a similar weight of the gastrocnemius in air- and CS- exposed TNF- $\alpha$ R2 KO mice, while significant loss of muscle mass was observed in CSexposed WT and TNF- $\alpha$ R1 KO mice compared with their airexposed littermates (data not shown). These findings suggest that the failure to gain weight is related to muscle wasting (atrophy) in the mice exposed to CS. Further investigations are needed to elucidate how the TNF- $\alpha$ receptors are involved in muscle wasting of mice exposed to CS.

In conclusion, the present authors confirm the importance of tumour necrosis factor- $\alpha$ in the pathogenesis of chronic obstructive pulmonary disease. In addition, the current findings in this murine model of chronic obstructive pulmonary disease suggests that both tumour necrosis factor- $\alpha$ receptors are involved in long-term cigarette smoke-induced pulmonary inflammation and emphysema. Interestingly, the contribution of tumour necrosis factor- $\alpha$ receptor $p 75$ is the most prominent. Moreover, the systemic effects of chronic obstructive pulmonary disease, such as a failure to gain weight, might also be mediated by tumour necrosis factor- $\alpha$ receptor p75 signalling.

\section{ACKNOWLEDGEMENTS}

The authors would like to gratefully acknowledge the skilful technical assistance of E. Castrique, I. De Borle, P. Degryze, K. De Saedeleer, M. Mouton, A. Neesen and C. Snauwaert. They would also like to give many thanks to N. D'haese for the excellent dissections of skeletal muscles.

\section{REFERENCES}

1 Murray CJ, Lopez AD. Alternative projections of mortality and disability by cause 1990-2020: Global Burden of Disease Study. Lancet 1997; 349: 1498-1504.

2 Pauwels RA, Rabe KF. Burden and clinical features of chronic obstructive pulmonary disease (COPD). Lancet 2004; 364: 613-620.

3 Pauwels RA, Buist AS, Calverley PM, Jenkins CR, Hurd SS. Global strategy for the diagnosis, management, and prevention of chronic obstructive pulmonary disease. NHLBI/WHO Global Initiative for Chronic Obstructive Lung Disease (GOLD) Workshop summary. Am J Respir Crit Care Med 2001; 163: 1256-1276. 
4 Schols AM, Buurman WA, Staal van den Brekel AJ, Dentener MA, Wouters EF. Evidence for a relation between metabolic derangements and increased levels of inflammatory mediators in a subgroup of patients with chronic obstructive pulmonary disease. Thorax 1996; 51: 819-824.

5 Di Francia M, Barbier D, Mege JL, Orehek J. Tumor necrosis factor-alpha levels and weight loss in chronic obstructive pulmonary disease. Am J Respir Crit Care Med 1994; 150: 1453-1455.

6 Bazzoni F, Beutler B. The tumor necrosis factor ligand and receptor families. $N$ Engl J Med 1996; 334: 1717-1725.

7 Churg A, Dai J, Tai H, Xie C, Wright JL. Tumor necrosis factor-alpha is central to acute cigarette smoke-induced inflammation and connective tissue breakdown. Am J Respir Crit Care Med 2002; 166: 849-854.

8 Gosset P, Perez T, Lassalle P, et al. Increased TNF-alpha secretion by alveolar macrophages from patients with rheumatoid arthritis. Am Rev Respir Dis 1991; 143: 593-597.

9 Millar AB, Miller RF, Foley NM, Meager A, Semple SJ, Rook GA. Production of tumor necrosis factor-alpha by blood and lung mononuclear phagocytes from patients with human immunodeficiency virus-related lung disease. Am J Respir Cell Mol Biol 1991; 5: 144-148.

10 Vuillemenot BR, Rodriguez JF, Hoyle GW. Lymphoid tissue and emphysema in the lungs of transgenic mice inducibly expressing tumor necrosis factor-alpha. Am J Respir Cell Mol Biol 2004; 30: 438-448.

11 Vandenabeele P, Declercq W, Beyaert R, Fiers W. Two tumour necrosis factor receptors: structure and function. Trends Cell Biol 1995; 5: 392-399.

12 Keatings VM, Collins PD, Scott DM, Barnes PJ. Differences in interleukin-8 and tumor necrosis factor-alpha in induced sputum from patients with chronic obstructive pulmonary disease or asthma. Am J Respir Crit Care Med 1996; 153: 530-534.

13 Kuschner WG, D'Alessandro A, Wong H, Blanc PD. Dosedependent cigarette smoking-related inflammatory responses in healthy adults. Eur Respir J 1996; 9: 1989-1994.

14 Takabatake N, Nakamura $\mathrm{H}$, Abe S, et al. The relationship between chronic hypoxemia and activation of the tumor necrosis factor-alpha system in patients with chronic obstructive pulmonary disease. Am J Respir Crit Care Med 2000; 161: 1179-1184.

15 McCrea KA, Ensor JE, Nall K, Bleecker ER, Hasday JD. Altered cytokine regulation in the lungs of cigarette smokers. Am J Respir Crit Care Med 1994; 150: 696-703.

16 Ouyang Y, Virasch N, Hao P, et al. Suppression of human IL-1beta, IL-2, IFN-gamma, and TNF-alpha production by cigarette smoke extracts. J Allergy Clin Immunol 2000; 106: 280-287.

17 Wouters EF, Creutzberg EC, Schols AM. Systemic effects in COPD. Chest 2002; 121: Suppl. 5, 127S-130S.

18 Hehlgans T, Mannel DN. The TNF-TNF receptor system. Biol Chem 2002; 383: 1581-1585.

19 Erickson SL, de Sauvage FJ, Kikly K, et al. Decreased sensitivity to tumour-necrosis factor but normal T-cell development in TNF receptor-2-deficient mice. Nature 1994; 372: 560-563.
20 Peschon JJ, Torrance DS, Stocking KL, et al. TNF receptordeficient mice reveal divergent roles for p55 and p75 in several models of inflammation. J Immunol 1998; 160: 943-952.

21 Pandey M, Tuncman G, Hotamisligil GS, Samad F. Divergent roles for p55 and p75 TNF-alpha receptors in the induction of plasminogen activator inhibitor-1. Am J Pathol 2003; 162: 933-941.

22 Akassoglou K, Douni E, Bauer J, Lassmann H, Kollias G, Probert L. Exclusive tumor necrosis factor (TNF) signaling by the p75TNF receptor triggers inflammatory ischemia in the CNS of transgenic mice. Proc Natl Acad Sci USA 2003; 100: 709-714.

23 Vernooy JH, Kucukaycan M, Jacobs JA, et al. Local and systemic inflammation in patients with chronic obstructive pulmonary disease: soluble tumor necrosis factor receptors are increased in sputum. Am J Respir Crit Care Med 2002; 166: 1218-1224.

24 Churg A, Wang RD, Tai H, Wang X, Xie C, Wright JL. Tumor necrosis factor-alpha drives $70 \%$ of cigarette smoke-induced emphysema in the mouse. Am J Respir Crit Care Med 2004; 170: 492-498.

25 Lucey EC, Keane J, Kuang PP, Snider GL, Goldstein RH. Severity of elastase-induced emphysema is decreased in tumor necrosis factor-alpha and interleukin-1beta receptor-deficient mice. Lab Invest 2002; 82: 79-85.

26 D'hulst A, Vermaelen K, Brusselle GG, Joos G, Pauwels R. Time course of cigarette smoke-induced pulmonary inflammation in mice. Eur Respir J 2005; 26: 204-213.

27 Vermaelen KY, Carro-Muino I, Lambrecht BN, Pauwels RA. Specific migratory dendritic cells rapidly transport antigen from the airways to the thoracic lymph nodes. J Exp Med 2001; 193: 51-60.

28 Thurlbeck WM. Measurement of pulmonary emphysema. Am Rev Respir Dis 1967; 95: 752-764.

29 Saetta M, Shiner RJ, Angus GE, et al. Destructive index: a measurement of lung parenchymal destruction in smokers. Am Rev Respir Dis 1985; 131: 764-769.

30 Aoshiba K, Yokohori N, Nagai A. Alveolar wall apoptosis causes lung destruction and emphysematous changes. Am J Respir Cell Mol Biol 2003; 28: 555-562.

31 Barnes PJ, Shapiro SD, Pauwels RA. Chronic obstructive pulmonary disease: molecular and cellular mechanisms. Eur Respir J 2003; 22: 672-688.

32 Di Stefano A, Caramori G, Ricciardolo FL, Capelli A, Adcock IM, Donner CF. Cellular and molecular mechanisms in chronic obstructive pulmonary disease: an overview. Clin Exp Allergy 2004; 34: 1156-1167.

33 Tartaglia LA, Goeddel DV, Reynolds C, et al. Stimulation of human T-cell proliferation by specific activation of the 75kDa tumor necrosis factor receptor. J Immunol 1993; 151: 4637-4641.

34 Holt PG, Haining S, Nelson DJ, Sedgwick JD. Origin and steady-state turnover of class II MHC-bearing dendritic cells in the epithelium of the conducting airways. J Immunol 1994; 153: 256-261.

35 Steinman RM. The dendritic cell system and its role in immunogenicity. Annu Rev Immunol 1991; 9: 271-296.

36 Wang B, Fujisawa H, Zhuang L, et al. Depressed Langerhans cell migration and reduced contact hypersensitivity response in mice lacking TNF receptor p75. J Immunol 1997; 159: 6148-6155. 
37 Winzler C, Rovere $\mathrm{P}$, Rescigno $\mathrm{M}$, et al. Maturation stages of mouse dendritic cells in growth factor-dependent longterm cultures. J Exp Med 1997; 185: 317-328.

38 Hart DN. Dendritic cells: unique leukocyte populations which control the primary immune response. Blood 1997; 90: 3245-3287.

39 Hautamaki RD, Kobayashi DK, Senior RM, Shapiro SD. Requirement for macrophage elastase for cigarette smokeinduced emphysema in mice. Science 1997; 277: 2002-2004.

40 Bracke K, Cataldo D, Maes T, et al. Matrix metalloproteinase12 and cathepsin D expression in pulmonary macrophages and dendritic cells of cigarette smoking mice. Int Arch Allergy Immunol 2005; 138: 169-179.

41 Kasahara Y, Tuder RM, Cool CD, Lynch DA, Flores SC, Voelkel NF. Endothelial cell death and decreased expression of vascular endothelial growth factor and vascular endothelial growth factor receptor 2 in emphysema. Am J Respir Crit Care Med 2001; 163: 737-744.

42 Tuder RM, Petrache I, Elias JA, Voelkel NF, Henson PM. Apoptosis and emphysema: the missing link. Am J Respir Cell Mol Biol 2003; 28: 551-554.

43 Liu ZG. Molecular mechanism of TNF signaling and beyond. Cell Res 2005; 15: 24-27.
44 Agusti AG, Noguera A, Sauleda J, Sala E, Pons J, Busquets $X$. Systemic effects of chronic obstructive pulmonary disease. Eur Respir J 2003; 21: 347-360.

45 Schols AM, Slangen J, Volovics L, Wouters EF. Weight loss is a reversible factor in the prognosis of chronic obstructive pulmonary disease. Am J Respir Crit Care Med 1998; 157: 1791-1797.

46 Landbo C, Prescott E, Lange P, Vestbo J, Almdal TP. Prognostic value of nutritional status in chronic obstructive pulmonary disease. Am J Respir Crit Care Med 1999; 160: 1856-1861.

47 Bartalesi B, Cavarra E, Fineschi S, et al. Different lung responses to cigarette smoke in two strains of mice sensitive to oxidants. Eur Respir J 2005; 25: 15-22.

48 Wager-Srdar SA, Levine AS, Morley JE, Hoidal JR, Niewoehner DE. Effects of cigarette smoke and nicotine on feeding and energy. Physiol Behav 1984; 32: 389-395.

49 Schols AM, Soeters PB, Dingemans AM, Mostert R, Frantzen PJ, Wouters EF. Prevalence and characteristics of nutritional depletion in patients with stable COPD eligible for pulmonary rehabilitation. Am Rev Respir Dis 1993; 147: 1151-1156. 